\title{
SALINIDADE NO DESENVOLVIMENTO DE CULTIVARES DE ALFACE
}

\section{Rogério Rangel Rodrigues ${ }^{1}$, Ana Paula Almeida Bertossi ${ }^{2}$, Giovanni de Oliveira} Garcia $^{3}$, Jéferson Rezende de Almeida ${ }^{4}$, Eduardo Assis da Silva ${ }^{5}$

1. Mestre em Produção Vegetal. Doutorando em Recursos Hídricos em Sistemas Agrícolas pelo Programa de Pós-graduação da Universidade Federal de Lavras, Lavras-MG, Brasil (rogeriorr7@hotmail.com)

2. Mestre em Produção Vegetal, Doutoranda do Programa de Pós-graduação em Produção Vegetal do Centro de Ciências Agrárias da Universidade Federal do Espírito Santo, CCA/UFES, Alegre-ES, Brasil

3. Prof. Dr. do Departamento de Engenharia Rural, CCA/UFES, Alegre-ES, Brasil 4. Biólogo, Alegre-ES, Brasil

5. Engenheiro Agrônomo, Alegre-ES, Brasil

Recebido em: 16/11/2015 - Aprovado em: 10/12/2015 - Publicado em: 21/12/2015 DOI: http://dx.doi.org/10.18677/Agrarian_Academy_019

\begin{abstract}
RESUMO
A alface (Lactuca sativa L.) é uma das hortaliças folhosa mais consumida mundialmente. Essa cultura é exigente em água, além de apresentar sensibilidade à salinidade da água de irrigação. Nesse contexto, objetivando avaliar a resposta de diferentes cultivares de alface a salinidade da água de irrigação, foi conduzido um experimento em condições de ambiente protegido, no Centro de Ciências Agrárias da Universidade Federal do Espírito Santo (CCA-UFES), município de Alegre-ES. O delineamento experimental utilizado foi o inteiramente casualizado, arranjados em esquema fatorial $3 \times 4$, com quatro repetições, sendo cada unidade experimental representada por um vaso (capacidade para $4 \mathrm{dm}^{3}$ ) contendo uma planta. Os tratamentos resultaram da combinação de três cultivares de alface (Brasil 221, do tipo lisa, Alface Repolhuda e Alface Americano, do tipo crespa) com quatro níveis de salinidade da água de irrigação, que foram: 0,1 (água da torneira); 0,5; 1,5 e 4,0 dS $\mathrm{m}^{-1}$, de modo que os valores contemplassem classes de baixa a muito alta salinidade de acordo com a classificação do Laboratório de Salinidade dos Estados Unidos. Os resultados revelaram que a salinidade da água de irrigação, acima de $1,5 \mathrm{dS} \mathrm{m}^{-1}$, reduziu o crescimento e o consumo de água pelas plantas de forma linear decrescente.
\end{abstract}

PALAVRAS- CHAVE: Lactuca sativa L., salinidade, água.

\section{SALINITY IN THE DEVELOPMENT OF CULTIVARS OF LETTUCE}

\begin{abstract}
Lettuce (Lactuca sativa L.) is one of the more leafy vegetables consumed worldwide. This culture is demanding in water, and be sensitive to salinity of irrigation water. In this context, to evaluate the response of different cultivars of lettuce to salinity of irrigation water, an experiment was conducted in protected environment at the Center
\end{abstract}


for Agricultural Sciences, Federal University of Espírito Santo (CCA-UFES), municipality of Alegre - ES. The experimental design was completely randomized in a factorial arrangement $3 \times 4$ with four replications, each experimental unit represented by a vessel (up to $4 \mathrm{dm}^{3}$ ) containing a plant. The treatments resulted from the combination of three varieties of lettuce (Brazil 221, the smooth type, Lettuce and cabbage American lettuce, the curly type) with four levels of salinity of irrigation water, which were: 0.1 (tap water); $0.5,1.5$ and $4.0 \mathrm{dS} \mathrm{m}^{-1}$, so that the values contemplated classes of low to very high salt according to the classification of salinity Laboratory in the United States. The results showed that the salinity of the irrigation water above $1.5 \mathrm{dS} \mathrm{m} \mathrm{m}^{-1}$, reduced the growth and consumption of water by plants of decreasing linearly.

KEYWORDS: Lactuca sativa L., salinity, water.

\section{INTRODUÇÃO}

A alface (Lactuca sativa L.), no agronegócio de hortaliças, possibilita a geração de grande número de empregos devido à elevada exigência de mão-de-obra. Também é a principal hortaliça consumida pela população, tanto pelo sabor e qualidade nutricional quanto pelo preço acessível ao consumidor. Todavia, para que essa cultura alcance seu máximo desenvolvimento, é de suma importância o favorecimento de um conjunto de fatores bióticos e abióticos, como o suprimento nutricional e o fornecimento hídrico em quantidade e qualidade satisfatória (SILVA et al., 2008).

Um dos problemas que podem afetar o pleno desenvolvimento dessa cultura é a utilização de água salina, que inibe o crescimento vegetal por efeito osmótico. Para ALVES et al. (2011), o problema da salinização pode ocorrer com o uso de água doce em condições de má drenagem do solo e de manejo incorreto da irrigação, e com o emprego de águas salobras, o processo da salinização são potencializadas.

Segundo AYERS \& WESTCOT (1999), a alface pode ser considerada como 'moderadamente sensível' à salinidade. Porém, essa tolerância depende da cultivar, do estádio fenológico, do tipo de sais, da intensidade e duração do estresse salino (TAIZ \& ZEIGER, 2009).

OLIVEIRA et al. (2011) ao avaliarem o desempenho de cultivares de alface em condições de salinidade observaram uma redução no desenvolvimento das plantas com o aumento da salinidade da água, o nível de resposta variou entre as cultivares estudadas.

Diante da importância da alface e da necessidade de estudos avaliem seu comportamento em condições de estresse salino, este trabalho teve como objetivo avaliar o desenvolvimento de três cultivares de alface (Brasil 221, do tipo lisa; alface Repolhuda e alface Americana do tipo crespa) irrigadas com água salina em diferentes níveis de condutividade elétrica.

\section{MATERIAL E MÉTODOS}

O experimento foi conduzido no período de maio a junho de 2012, em condições de ambiente protegido, no Centro de Ciências Agrárias da Universidade Federal do Espírito Santo (CCA-UFES) no município de Alegre - ES, localizado sob

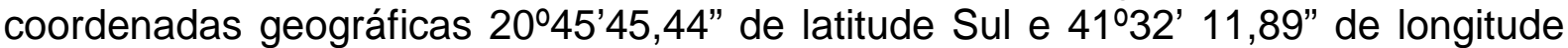
oeste de Greenwich, com altitude de $269 \mathrm{~m}$. De acordo com a classificação de 
Köeppen o clima da região é do tipo "Aw" com estação seca no inverno, a temperatura anual média é de $23,1^{\circ} \mathrm{C}$ e a precipitação anual em torno de $1200 \mathrm{~mm}$.

O delineamento experimental utilizado foi 0 inteiramente casualizado, arranjados em esquema fatorial $3 \times 4$, com quatro repetições, sendo a unidade experimental representada por um vaso contendo uma planta. Os tratamentos resultaram da combinação de três cultivares de alface (Brasil 221, do tipo lisa, Alface Repolhuda e Alface Americano, do tipo crespa) com quatro níveis de salinidade da água de irrigação, que foram: 0,1 (água da torneira); 0,5; 1,5 e 4,0 dS m $\mathrm{de}^{-1}$, modo que os valores contemplassem classes de baixa a muito alta salinidade de acordo com a classificação do Laboratório de Salinidade dos Estados Unidos (UNIVERSITY OF CALIFORNIA, 1974). Os diferentes níveis salinos foram obtidos pela dissolução de cloreto de sódio $(\mathrm{NaCl})$ e cloreto de cálcio $\left(\mathrm{CaCl}_{2}\right)$ em água proveniente do sistema de abastecimento do campus do CCA-UFES.

O plantio foi realizado com mudas produzidas em bandejas de poliestireno expandido de 128 células, sendo as sementes semeadas em substrato comercial. Quando as mudas apresentaram cerca de 3 a 4 folhas definitivas, foram transplantadas para vasos de plástico com capacidade para $4 \mathrm{dm}^{3}$.

O material de solo coletado foi peneirado em malha de $2 \mathrm{~mm}$, sendo retirada uma subamostra para caracterização química e física (EMBRAPA, 1997), cujo as características estão apresentadas na Tabela 1.

TABELA 1. Características físico-químicas do solo utilizado no experimento

\begin{tabular}{ccc}
\hline Parâmetros & Unidades & Resultados \\
\hline $\mathrm{pH}\left(\mathrm{H}_{2} \mathrm{O}\right)$ & - & 6,0 \\
$\mathrm{P}$ & $\mathrm{mg} \mathrm{dm}^{-3}$ & 3,0 \\
$\mathrm{~K}^{+}$ & $\mathrm{cmol}_{\mathrm{c}} \mathrm{dm}^{-3}$ & 5,0 \\
$\mathrm{Ca}^{2+}$ & $\mathrm{cmol}_{\mathrm{c}} \mathrm{dm}^{-3}$ & 1,4 \\
$\mathrm{Mg}^{2+}$ & $\mathrm{Cmol}_{\mathrm{c}} \mathrm{dm}^{-3}$ & 1,0 \\
$\mathrm{Na}^{+}$ & $\mathrm{cmol}_{\mathrm{c}} \mathrm{dm}^{-3}$ & 0,4 \\
$\mathrm{Al}^{3+}$ & $\mathrm{cmol}_{\mathrm{c}} \mathrm{dm}^{-3}$ & 0,0 \\
$\mathrm{Areia}$ & $\%$ & 46,0 \\
Silte & $\%$ & 9,0 \\
Argila & $\%$ & 45,0 \\
\hline Textura & \multicolumn{3}{c}{} \\
\hline
\end{tabular}

Foram determinadas as características físico-hídricas do solo para o cálculo da irrigação real necessária ao desenvolvimento da cultura (Tabela 2). A densidade do solo foi obtida pelo método da proveta, a umidade do solo na capacidade de campo à tensão de $0,01 \mathrm{MPa}$ e a umidade do solo no ponto de murcha permanente à tensão de 1,5 MPa, com o auxílio do extrator de Richards, de acordo com EMBRAPA (1997).

TABELA 2: Característica físico-hídrica do solo utilizado no experimento

\begin{tabular}{cccc}
\hline CC & PMP & Ds \\
\hline & $---\%$--- & & $\mathrm{g} \mathrm{cm}^{-3}$ \\
\cline { 1 - 2 } & & 14,1 & 1,21 \\
\hline
\end{tabular}


Para a realização das irrigações foi determinado o peso de cada parcela experimental na capacidade de campo, chamado neste trabalho de peso na capacidade de campo inicial $\left(P_{c c i}\right)$. Para a obtenção do $P_{c c i}$ todos os vasos já com as mudas plantadas foram saturados com água e deixados em drenagem livre por 48 horas a fim de que o solo atingisse a capacidade de campo. Após a determinação do $P_{\text {cci }}$ de cada parcela experimental foi calculado o peso critico para irrigação de cada parcela experimental $\left(P_{c i}\right)$, utilizando um fator de disponibilidade hídrica (f) de 0,3, valor este recomendado para verduras e legumes (MANTOVANI et al., 2009).

Após determinar-se o $\mathrm{P}_{\text {cci }}$ de cada parcela experimental foi calculada a lâmina de irrigação $\left(L_{l}\right)$ correspondente ao fator de disponibilidade hídrica utilizada. Para isso, foi calculada a água disponível do solo (AD), considerando os valores de umidade gravimétrica na capacidade de campo (CC) e no ponto de murcha permanente (PMP), utilizando-se a equação 1 (CENTURION \& ANDREOLI, 2000).

$$
\mathrm{AD}=\mathrm{CC}-\mathrm{PMP}
$$

Em que:

AD - água disponível em \% em peso;

CC - Capacidade de campo em \% em peso; e

PMP - Ponto de murcha permanente em \% em peso.

A partir da água disponível, foi estabelecida a umidade do solo correspondente ao fator de disponibilidade hídrica $(0,3)$, sendo utilizada no cálculo da lâmina de irrigação necessária para elevar o teor de umidade do solo à capacidade de campo, para isto utilizou-se a equação 2 (HASSANLI et al., 2010):

$$
\mathrm{L}_{\mathrm{I}}=\left(\frac{\theta_{\mathrm{cC}}-\theta_{\text {atual }}}{10}\right) * \mathrm{Ds} * \mathrm{~h}
$$

Em que: $L_{1}$ - lâmina de irrigação em $\mathrm{mm} ; \theta_{c c}$ - umidade na capacidade de campo, \% em em peso; $\theta_{\text {atual }}$ - umidade atual do solo relativo ao fator de disponibilidade de água no solo (f de 0,3 ), correspondendo a $30 \%$ da AD; Ds densidade do solo, em $\mathrm{g} / \mathrm{cm}^{3}$; e $\mathrm{h}$ - altura de solo utilizado no vaso, em $\mathrm{cm}$.

Para transformar a lâmina de irrigação $\left(L_{l}\right)$ em volume (mL/vaso), foi multiplicado a $L_{1}$ pela área útil do vaso. $O$ solo de cada vaso foi coberto com plástico branco para minimizar a perda de água por evaporação, visando garantir que a água perdida em cada parcela experimental fosse apenas proveniente da transpiração das plantas. Ao final da tarde de cada dia todas as parcelas eram pesadas em uma balança eletrônica e a irrigação era feita toda vez que o $P_{c i}$ fosse atingindo, voltando a umidade do solo para a umidade na capacidade de campo inicial $\left(\mathrm{P}_{\text {cci }}\right)$.

Outro parâmetro avaliado foi o coeficiente de transpiração (CT), que é um indicador utilizado na comparação da eficiência do uso da água pelas plantas. O CT fornece a quantidade de água em litros necessários para a produção de $1 \mathrm{~kg}$ de biomassa ( $\mathrm{L} \mathrm{H}_{2} \mathrm{O} \mathrm{kg}{ }^{-1}$ matéria seca). O turno de rega foi de três dias, sendo utilizada uma lâmina de lixiviação de $30 \%$ da água reposta em cada parcela, a fim de manter a condutividade elétrica do estrato de saturação do solo favorável ao desenvolvimento da cultura.

A colheita da alface foi realizada aos 35 dias após transplantio e foram mensuradas as variáveis: massa da parte aérea fresca (MPAF), massa da parte 
aérea seca (MPAS), massa da raiz seca (MRS), número de folhas (NF), transpiração relativa acumulada (TRA) e, o coeficiente de transpiração (CT). As plantas foram levadas à estufa de circulação forçada, na temperatura de $65^{\circ} \mathrm{C}$, até obtenção de massa constante no tempo. Os valores de massa de matéria da planta fresca e seca foram determinados em balança com precisão de 0,001 .

$\mathrm{O}$ fator salinidade da água e cultivares de alface foram estudados mediante análises de variância, aplicando-se regressão para o fator salinidade e teste de Tukey para comparação entre as médias para as cultivares.

\section{RESULTADOS E DISCUSSÕES}

$\mathrm{Na}$ Tabela 1 estão apresentados os valores dos coeficientes de transpiração (CT) em função das diferentes concentrações de sais na água de irrigação para cada cultivar de alface avaliada.

TABELA 1-Coeficiente de transpiração ( $\mathrm{L} \mathrm{H}_{2} \mathrm{O} \mathrm{Kg}{ }^{-1}$ de biomassa), para três cultivares de alface (Brasil 221, do tipo lisa, Alface Repolhuda e Alface Americano, do tipo crespa), submetidas a quatro níveis de salinidade da água de irrigação

\begin{tabular}{ccccc}
\hline Cultivares & \multicolumn{4}{c}{ Condutividade elétrica } \\
\hline & 0,1 & 0,5 & 1,5 & 4 \\
\cline { 2 - 5 } & 614,48 & 624,73 & 665,63 & 669,47 \\
Brasil 221 & 468,86 & 371,58 & 444,44 & 479,88 \\
Repolhuda & 428,68 & 424,10 & 434,02 & 437,16 \\
Americana &
\end{tabular}

Nas concentrações salinas até $0,5 \mathrm{dS} \mathrm{m}^{-1}$ nota-se que as três cultivares de alface utilizaram menos água para a produção de $1 \mathrm{~kg}$ de biomassa, mostrando maior eficiência quando comparadas às plantas que foram submetidas à salinidades maiores, atingindo valores máximo de coeficiente de transpiração na concentração salina de $4 \mathrm{dS} \mathrm{m}^{-1}$.

Os valores de CT encontrados no presente estudo são menores que os valores encontrados por BALBINO et al. (2003) na cultura da soja $\left(700 \mathrm{~L} \mathrm{H}_{2} \mathrm{O} \mathrm{kg}{ }^{-1}\right.$ de biomassa), e próximos aos encontrados pelo mesmo autor para o milho (300 a $400 \mathrm{~L}$ $\mathrm{H}_{2} \mathrm{O} \mathrm{kg}{ }^{-1}$ de biomassa). $\mathrm{O}$ aumento no consumo de água pelas cultivares para a produção de $1 \mathrm{Kg}$ de biomassa seca ocorreu em resposta à saturação de sais na água da irrigação, pois durante o efeito da salinidade, determinados processos são danificados, tais como: síntese de proteínas, metabolismo de lipídios e fotossíntese.

De acordo com a Tabela 2, houve interação significativa entre as cultivares estudadas $e$ as concentrações de sais na água de irrigação para todas as características avaliadas. Desta forma, procedeu-se o estudo de um fator dentro dos níveis do outro fator. 
TABELA 2. Resumo da ANOVA e valores médios de massa da parte aérea fresca (MPAF), massa da parte aérea seca (MPAS), massa da raiz seca (MRS), número de folhas (NF) e transpiração relativa acumulada (TRA)

\begin{tabular}{ccccccc}
\hline & $\mathrm{G}$ & $\mathrm{QM}$ & & & \\
\hline FV & $\mathrm{GL}$ & MFPA & MSPA & MSR & NF & TRA \\
\hline CULT*CEa $^{*}$ C & $997,06^{* *}$ & $5,62^{* *}$ & $0,99^{* *}$ & $8,74^{* *}$ & $0,45^{\star *}$ \\
Resíduo & 36 & 72,63 & 0,16 & 0,75 & 1,84 & 0,62 \\
Total & 47 & & & & & \\
Média Geral & & 227,22 & 10,91 & 1,58 & 23,37 & 4,48 \\
CV (\%) & & 3,75 & 3,70 & 5,49 & 5,81 & 1,76 \\
\hline
\end{tabular}

${ }^{* *}$ Significativo a $1 \%$ de probabilidade pelo teste de $\mathrm{F}$.

Na Figura 1 está apresentado o teste de média para as variáveis massa da parte aérea fresca (MPAF) e massa da parte aérea seca (MPAS) das cultivares de alface nas diferentes concentrações de sais na água de irrigação.

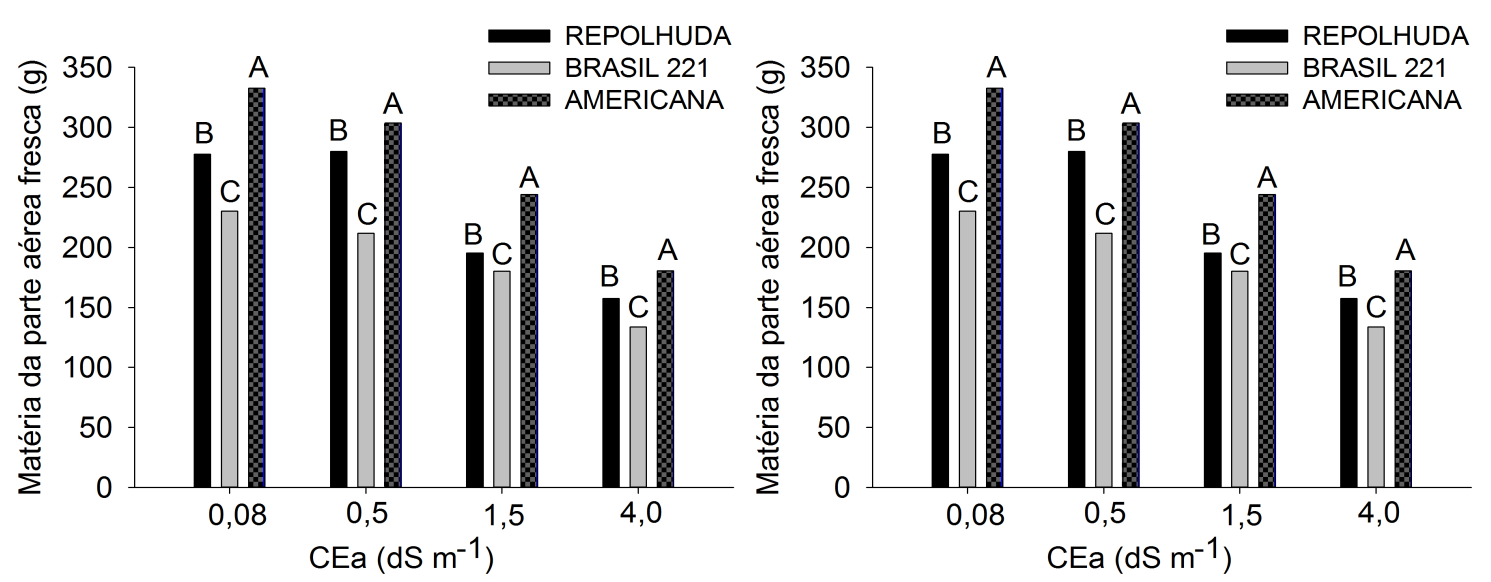

FIGURA 1. Teste de média para as variáveis massa da parte aérea fresca (MPAF) e massa da parte aérea seca (MPAS) das cultivares de alface nas diferentes condutividades elétricas na água de irrigação (CEa), sendo: 1 $=0,08 \mathrm{dS} \mathrm{m}^{-1} ; 2=0,5 \mathrm{dS} \mathrm{m}^{-1} ; 3=1,5 \mathrm{dS} \mathrm{m}^{-1}$ e $4=4,0 \mathrm{dS} \mathrm{m}^{-1}$. Coluna seguida pela mesma letra dentro de cada nível de salinidade não difere entre si a $5 \%$ de probabilidade pelo teste de Tukey.

Observa-se que para a variável MPAF e MPAS a cultivar Americana, do tipo crespa, apresentou o melhor resultados nas diferentes concentrações de sais na água de irrigação, diferindo das cultivares Repolhuda e Brasil 221. As diferenças na tolerância das cultivares de alface aos diferentes níveis de salinidade da água utilizada para a produção de biomassa também foram encontradas por alguns autores, como OLIVEIRA et al. (2011) trabalhando com as cultivares Mônica SF31, Grandes Lagos 659, Veneranda, Folha Roxa, Quatro Estações e Stella; FREIRE et al. (2009) trabalhando com as cultivares Mônica SF31, Grandes Lagos 659, Veneranda, Folha Roxa, Quatro Estações e Stella; e PAULUS et al. (2010) trabalhando com as cultivares Verônica e Pira Roxa.

$\mathrm{Na}$ Figura 2 estão apresentados os dados do teste de média para massa da raiz seca (MRS) e o número de folhas (NF) das cultivares de alface nas diferentes concentrações de sais na água de irrigação.

AGRARIAN ACADEMY, Centro Científico Conhecer - Goiânia, v.2, n.04; p. 75 

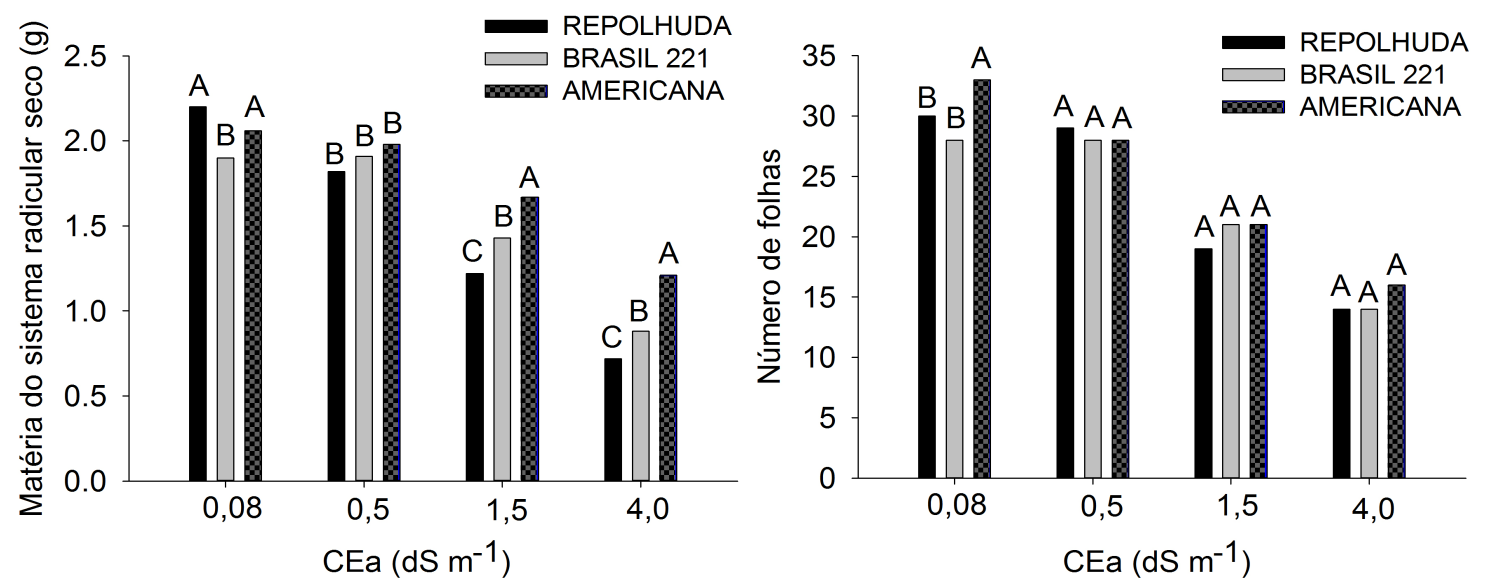

FIGURA 2. Teste de média para as variáveis massa da raiz seca (MRS) e número de folhas (NF) das cultivares de alface nas diferentes condutividades elétricas na água de irrigação (CEa), sendo: $1=0,08 \mathrm{dS} \mathrm{m}^{-1} ; 2=0,5 \mathrm{dS} \mathrm{m}^{-1} ; 3=1,5 \mathrm{dS} \mathrm{m}^{-1}$ e $4=4,0 \mathrm{dS} \mathrm{m}^{-1}$. Coluna seguida pela mesma letra dentro de cada nível de salinidade não difere entre si a $5 \%$ de probabilidade pelo teste de Tukey.

A análise da MRS demonstra que houve diferenças significativas entre as cultivares estudadas somente a partir da condutividade elétrica da água de irrigação $3\left(1,5 \mathrm{dS} \mathrm{m}^{-1}\right)$. Para a variável $\mathrm{NF}$, praticamente não houve diferença estatística entre as cultivares estudadas. Porém, a análise isolada do NF das cultivares pode induzir a conclusões equivocadas, pois a contagem das folhas foi feita tanto para folhas pequenas quanto para folhas grandes. No entanto, foi visível que a partir do nível de salinidade $3\left(1,5 \mathrm{dS} \mathrm{m}^{-1}\right) \circ$ tamanho comercial das folhas das cultivares diminuiu.

O maior número de folhas foi observado até o nível de salinidade $2(0,5 \mathrm{dS} \mathrm{m}$ ${ }^{1}$ ). No entanto, MAGALHÃES et al. (2010), ao avaliarem diferentes níveis de condutividade elétrica da água na produção de alface, encontraram resultados satisfatórios em condutividade elétrica até $3 \mathrm{dS} \mathrm{m}^{-1}$.

$\mathrm{Na}$ Figura 2 estão apresentados os dados do teste de média para a transpiração relativa acumulada (TRA) das cultivares de alface nas diferentes concentrações de sais na água de irrigação.

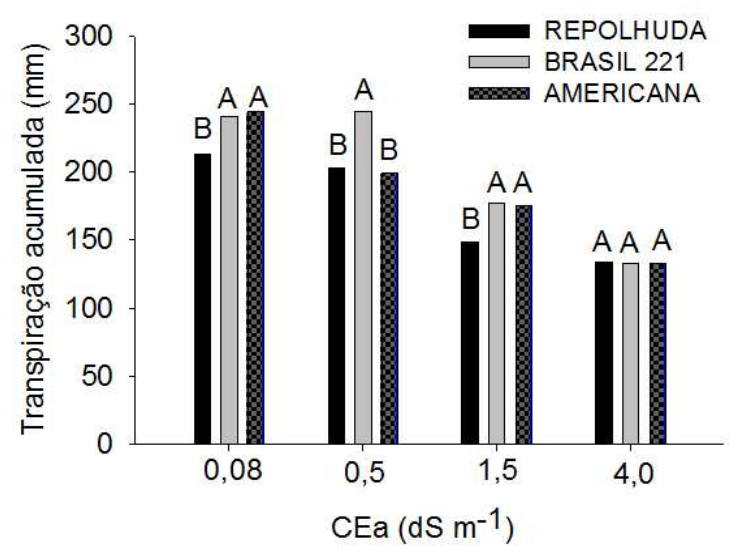

FIGURA 3. Teste de média para a variável transpiração acumulada (TA) das cultivares de alface nas diferentes condutividades elétricas na água de irrigação (CEa), sendo: $1=0,08 \mathrm{dS} \mathrm{m}^{-1} ; 2=0,5 \mathrm{dS} \mathrm{m}^{-1} ; 3=1,5 \mathrm{dS} \mathrm{m}^{-1}$ e $4=4,0 \mathrm{dS} \mathrm{m}^{-1}$. Coluna seguida pela mesma letra dentro de cada nível de salinidade não difere entre si a 5\% de probabilidade pelo teste de Tukey. 
A transpiração acumulada no período de desenvolvimento das cultivares de alface foi influenciada pelo crescente nível de sais na água de irrigação. No nível de salinidade $4\left(4,0 \mathrm{dS} \mathrm{m}^{-1}\right)$ as cultivares apresentaram os menores valores, não diferenciando estatisticamente. Possivelmente, o efeito osmótico da salinidade reduziu a disponibilidade de água para as plantas, contribuindo com o estresse hídrico, com redução progressiva da superfície transpiratória (RICHARDS, 1974).

O consumo de água pode ser influenciado tanto pela condutividade elétrica da água, quanto pelas cultivares utilizadas, o que foi observado por SOARES (2007) e VIANA et al., (2004) ao estudarem a influência de diferentes concentrações de sais na água no cultivo de alface. A resposta das plantas ao meio salino depende de suas características genéticas e das condições do meio, podendo cultivares diferentes apresentarem respostas distintas à salinidade.

$\mathrm{Na}$ Tabela 3 estão apresentadas as equações de regressão para a análise dos níveis de salinidade da água de irrigação em cada cultivar estudada.

TABELA 3. Equação de regressão e coeficiente de determinação $\left(R^{2}\right)$ para massa da parte aérea fresca (MPAF), massa da parte aérea seca (MPAS), massa da raiz seca (MRS) e transpiração relativa acumulada (TRA) das plantas de alface cultivadas em casa de vegetação e irrigada com água salina

\begin{tabular}{|c|c|c|}
\hline Cultivares* & Equação de regressão & $\mathrm{R}^{2}$ \\
\hline & Massa da parte aérea fresca (MPAF) & \\
\hline CV1 & MFPA $=297,33-37,251$ CEa & 0,8907 \\
\hline CV2 & MFPA $=109,06-12,353 \mathrm{CEa}$ & 0,9902 \\
\hline cV3 & MFPA $=157,15-19,531 \mathrm{CEa}$ & 0,9729 \\
\hline & Massa da parte aérea seca (MPAS) & \\
\hline CV1 & $\mathrm{MSPA}=7,7892-1,0102 \mathrm{CEa}$ & 0,8621 \\
\hline cV2 & $\mathrm{MSPA}=5,7262-0,5911 \mathrm{CEa}$ & 0,9499 \\
\hline cV3 & $\mathrm{MSPA}=8,2998-0,9541 \mathrm{CEa}$ & 0,9757 \\
\hline & Massa da raiz seca (MRS) & \\
\hline CV1 & $\mathrm{MSR}=1,6583-0,2545 \mathrm{CEa}$ & 0,9541 \\
\hline CV2 & MSR $=1,7605-0,2508 \mathrm{CEa}$ & 0,9642 \\
\hline CV3 & MSR $=1,6755-0,1544 C E a$ & 0,9643 \\
\hline & Número de folhas (NF) & \\
\hline CV1 & $N F=30,351-3,6947 \mathrm{CEa}$ & 0,9891 \\
\hline CV2 & $N F=31,824-4,1527 \mathrm{CEa}$ & 0,9671 \\
\hline CV3 & $N F=30,137-3,3588 \mathrm{CEa}$ & 0,9826 \\
\hline & Transpiração relativa acumulada (TRA) & \\
\hline CV1 & TRA $=5,9816-0,5925 \mathrm{CEa}$ & 0,9638 \\
\hline cV2 & TRA $=5,9762-0,6511 \mathrm{CEa}$ & 0,9627 \\
\hline cV3 & TRA $=5,9739-0,6218 \mathrm{CEa}$ & 0,9762 \\
\hline
\end{tabular}

${ }^{*}$ CV1 - Alface Repolhuda; CV2 - Brasil 221; CV3 - alface Americana.

Observa-se na Tabela 3 que as equações de regressão apresentaram um ótimo ajuste do tipo linear para todas as cultivares avaliadas, com coeficiente de 
determinação $\left(R^{2}\right)$ satisfatório, variando de 0,8621 a 0,9902. Na Figura 4, nota-se que a massa da parte aérea fresca (MPAF) e a massa da parte aérea seca (MPAS) das três cultivares estudadas, decresceram linearmente com 0 aumento da salinidade da água de irrigação.
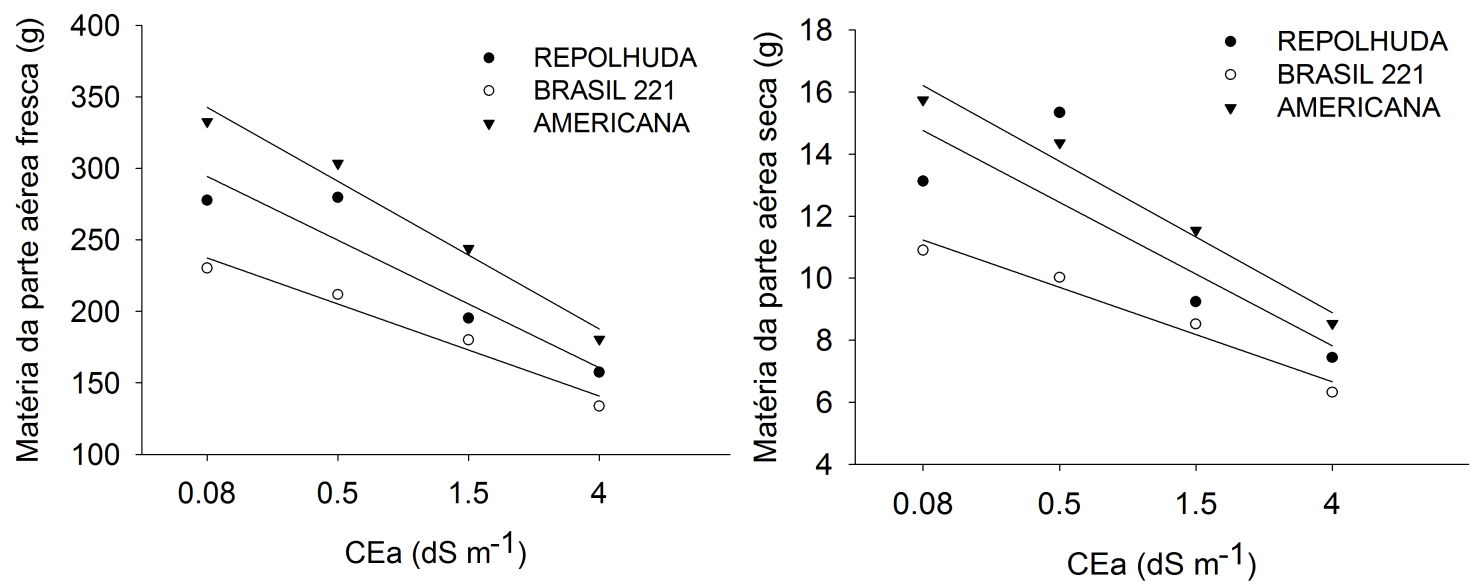

FIGURA 4: Análise de regressão da massa da parte aérea fresca (MPAF) e da massa da parte aérea seca (MPAS) das cultivares de alface nas diferentes condutividades elétricas na água de irrigação (CEa), sendo: $1=0,08 \mathrm{dS} \mathrm{m} \mathrm{m}^{-1} ; 2=0,5 \mathrm{dS} \mathrm{m} \mathrm{m}^{-1} ; 3=1,5 \mathrm{dS} \mathrm{m}^{-1}$ e $4=4,0 \mathrm{dS} \mathrm{m}^{-1}$.

PAULUS et al. (2010) ao avaliarem a produção de alface em hidroponia com água salina também observaram resposta linear e decrescente em duas cultivares de alface (Verônica e Pira roxa), constatando que houve redução da massa fresca de acordo com cada cultivar.

Para o acúmulo de massa da raiz seca (MRS) e do número de folhas (NF) das cultivares estudadas também se observou resposta linear decrescente com 0 aumento da salinidade da água de irrigação até o nível de salinidade 4 (4 dS $\left.\mathrm{m}^{-1}\right)$ (Figura 5).
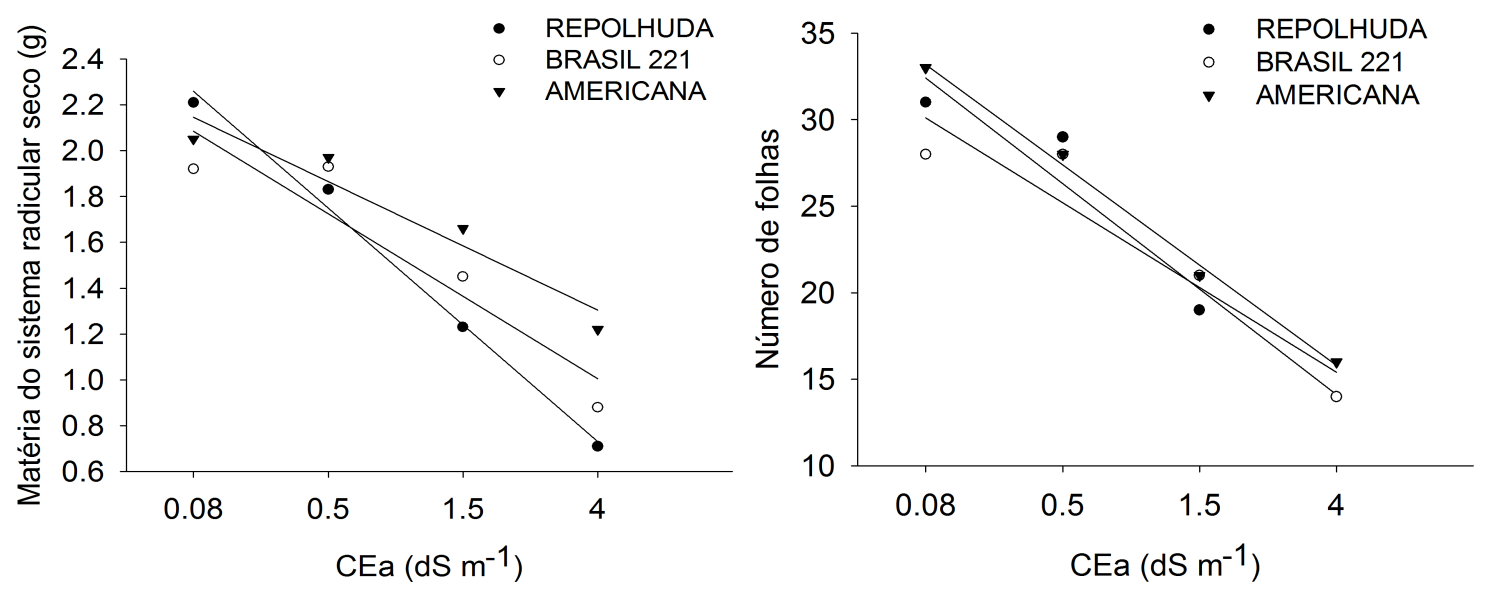

FIGURA 5. Análise de regressão da massa da raiz seca (MRS) e do número de folhas (NF) das cultivares de alface nas diferentes condutividades elétricas na água de irrigação (CEa), sendo: $1=0,08 \mathrm{dS} \mathrm{m}^{-1} ; 2=0,5 \mathrm{dS}$ $\mathrm{m}^{-1} ; 3=1,5 \mathrm{dS} \mathrm{m}^{-1}$ e $4=4,0 \mathrm{dS} \mathrm{m}^{-1}$. 
Semelhante ao acúmulo de massa fresca, a massa seca foi reduzida em todas as cultivares estudadas, entretanto, só foi observado efeito significativo com salinidade acima de $1,5 \mathrm{dS} \mathrm{m}^{-1}$. Resultados semelhantes foram encontrados por ANDRIOLO et al. (2005) ao avaliarem o desenvolvimento da alface cultivar Elba sob diferentes níveis de salinidade. A transpiração relativa acumulada durante 0 desenvolvimento das cultivares de alface está apresentada na Figura 6.

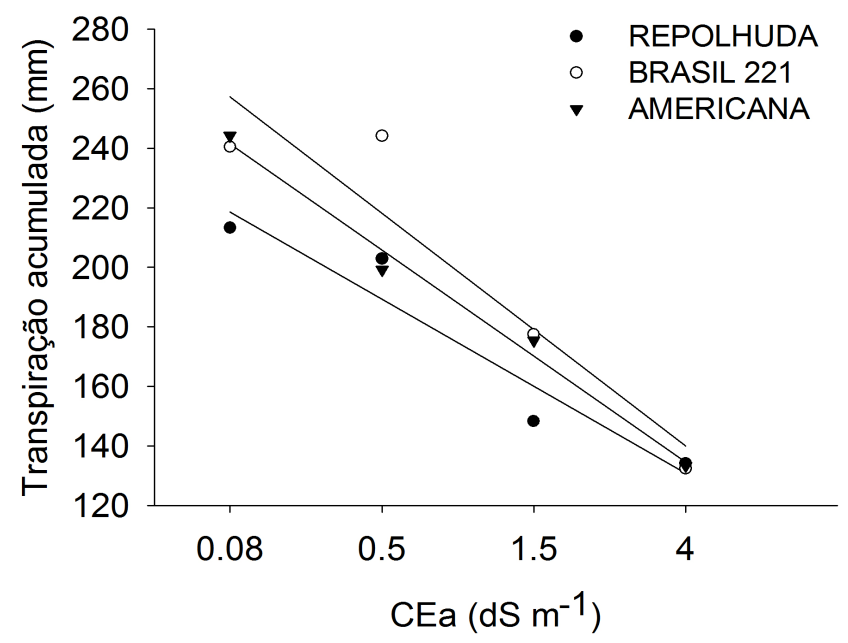

FIGURA 6. Análise de regressão da transpiração relativa acumulada (TRA) das cultivares de alface nas diferentes condutividades elétricas na água de irrigação (CEa), sendo: $1=0,08 \mathrm{dS} \mathrm{m} \mathrm{m}^{-1} ; 2=0,5 \mathrm{dS} \mathrm{m} \mathrm{m}^{-1} ; 3=1,5 \mathrm{dS} \mathrm{m}^{-1}$ e $4=4,0 \mathrm{dS} \mathrm{m}^{-1}$.

A transpiração acumulada decresceu linearmente com 0 aumento da concentração de sais na água de irrigação. Possivelmente, o efeito osmótico da salinidade reduziu a disponibilidade de água para a planta, contribuindo com o estresse hídrico, com redução progressiva da superfície transpiratória (RICHARDS, 1974).

A redução do consumo de água pelas plantas com o aumento da salinidade também foi verificada por VIANA et al., (2004), em mudas de alface da variedade Elba, cultivadas em vasos.

\section{CONCLUSÕES}

A utilização de níveis crescentes de sais na água de irrigação influenciou o desenvolvimento das cultivares de alface, diminuindo linearmente a massa da parte aérea fresca, a massa da parte aérea seca, o número de folhas e a massa da raiz seca.

A evapotranspiração das cultivares de alface foi reduzida com os níveis crescentes de sais na água de irrigação.

Foi observado efeito significativo no desenvolvimento das cultivares de alface nos níveis de salinidade acima de $1,5 \mathrm{dS} \mathrm{m}^{-1}$.

\section{REFERÊNCIAS}

ALVES, M. S.; SOARES, T. M.; SILVA, L. T.; FERNANDES, J. P.; OLIVEIRA, M. L. A.; PAZ, V. P. S. Estratégias de uso de água salobra na produção de alface em hidroponia NFT. Revista Brasileira de Engenharia Agrícola e Ambiental, v.15, n. 
5, p. 491-498, 2011. Disponível em: <http://dx.doi.org/10.1590/S141543662011000500009>. doi: 10.1590/S1415-43662011000500009

ANDRIOLO, J. L.; LUZ, G. L.; WITTER, M. H.; GODOI, R. S.; BARROS, G. T.; BORTOLOTTO, O. C. Growth and yield of lettuce plants under salinity. Horticultura Brasileira, v.23, p.931-934, 2005. Disponível em: <http://dx.doi.org/10.1590/S010205362005000400014>. doi: 10.1590/S0102-05362005000400014

AYERS, R. S.; WESTCOT, D. W. Water quality for agriculture. Roma: FAO, 1985. 174 p. Irrigation and Drainage Paper, 29, Rev. 1.

BALBINO, L. C.; BROSSARD, M; STONE, L. F.; LEPRUN, J. C. Estruturas e propriedades hidráulicas em latossolos sob cultivo na região do Cerrado. Rio de Janeiro: EMBRAPA, 2003. 44p.

EMBRAPA: Empresa brasileira de pesquisa agropecuária. Manual de métodos de análises de solo. 2.ed. Rio de Janeiro: Ministério da Agricultura e do Abastecimento, 1997.

FREIRE, A. G.; OLIVEIRA, F. A. de.; CARRILHO, M. J. S. de O.; OLIVEIRA, M. K. T. de.; FREITAS, D. C. de. Qualidade de cultivares de alface produzida em condições salinas. Revista Caatinga, v.22, n.4, p. 81-88. 2009.

HASSANLI, A. M.; AHMADIRAD, S.; BEECHAM, S. Evaluation of the influence of irrigation methods and water quality on sugar beet yield and water use efficiency. Agricultural Water Management, v. 97, p. 357-362, 2010.

MAGALHÃES, A. G.; MENEZES, D.; RESENDE, L. V.; BEZERRA NETO, E. Desempenho de cultivares de alface em cultivo hidropônico sob dois níveis de condutividade elétrica. Horticultura Brasileira, v.28, p. 316-320. 2010.

MANTOVANI, E. C.; BERNARDO, S.; PALARETTI, L. F. Irrigação: princípios e métodos. 2.ed., atual. eampl. Viçosa, MG: UFV, 2009. 355 p.

OLIVEIRA, F. A. de.; CARRILHO, M. J. S. de O.; MEDEIROS, J. F. de.; MARACAJÁ, P. B.; OLIVEIRA, M. K. T. de. Desempenho de cultivares de alface submetidas a diferentes níveis de salinidade da água de irrigação. Revista Brasileira de Engenharia Agrícola e Ambiental, v.15, n8, p. 771-777, 2011. Disponível em: <http://dx.doi.org/10.1590/S1415-43662011000800002> doi: 10.1590/S141543662011000800002

PAULUS, D.; DOURADO NETO, D.; FRIZZONE J. A.; SOARES T. M. Produção e indicadores fisiológicos de alface sob hidroponia com água salina. Horticultura Brasileira, v.28, n.1, p. 29-35, 2010. Disponível em: <http://dx.doi.org/10.1590/S0102-05362010000100006 > doi: 10.1590/S010205362010000100006

RICHARDS, L. A.Diagnostico y rehabilitacion de suelos salinos y sódicos. DAEUA. México. Editorial Limusa, 1974. 172 p. 
SILVA, J. K. M.; OLIVEIRA, F. A.; MARACAJÁ, P. B.; FREITAS, R. S.; MESQUITA, L. X. Efeito da salinidade e adubos orgânicos no desenvolvimento da rúcula. Revista Caatinga, v.21, n.5, p.30-35, 2008.

SOARES, T. M. Utilização de águas salobras no cultivo da alface em sistema hidropônico NFT com alternativa agrícola condizente ao semi-árido brasileiro. Escola Superior de Agricultura "Luiz de Queiroz", Universidade de São Paulo, Piracicaba, 267p. 2007. (Tese de Doutorado).

TAIZ, L.; ZEIGER, E. Fisiologia vegetal. 4.ed. Porto Alegre: Artmed, 2009. 819p.

UNIVERSITY OF CALIFORNIA.Guideline for Interpretation of Water Quality for Agriculture. Davis: Committee of consultants, 1974.13 p. Disponívelem<http://www.fao.org/docrep/003/t0234e/t0234e00.htm>.Acesso em: 29 abr. 2011.

VIANA, S. B. A.; FERNANDES, P. D.; GHEYI, H. R.; SOARES, F. A. L.; CARNEIRO, P. T. Índices morfofisiológicos e de produção de alface sob estresse salino. Revista Brasileira de Engenharia Agrícola e Ambiental, v.8, n. 1, p.23-30. 2004. Disponível em: <http://dx.doi.org/10.1590/S1415-43662004000100004 > doi: 10.1590/ S1415-43662004000100004 